\title{
Dental Caries, Fluorosis, and Fluoride Exposure in Michigan Schoolchildren
}

\author{
S.M. SZPUNAR ${ }^{1}$ and B.A. BURT
}

Program in Dental Public Health, School of Public Health II, The University of Michigan, Ann Arbor, Michigan $48109-2029$

\begin{abstract}
This study relates the prevalence of caries and fluorosis among Michigan children, residing in four different areas, to the various concentrations of $F$ in the communities" water supplies. Demographic information, details of $F$ history, and dental attendance data were collected by a questionnaire form filled out by parents. Children ages six to 12 were screened for caries by means of the NIDR criteria and for fluorosis by means of the TSIF index. Results pertain only to continuous residents and the permanent dentition. The prevalence of both caries and fluorosis was significantly associated with the $F$ concentration in the community water supply. Approximately $65 \%$ of all children were caries-free, ranging from $55.1 \%$ in fluoride-deficient Cadillac to $73.7 \%$ in Redford (1.0 ppm F). About $36 \%$ of all children had dental fluorosis, ranging from 12.2 in Cadillac to 51.2 in Richmond $(1.2 \mathrm{ppm})$. All of the fluorosis was very mild. From logistic regression, the prevalence of caries was significantly associated with age, dental attendance, and the use of a water supply fluoridated at $1.0 \mathrm{ppm}$. The odds of experiencing fluorosis increased at every $F$ level above the baseline (Cadillac), with the use of topical $F$ rinses, and with age. Results suggest that children in the four communities may be ingesting a similar level of $F$ from sources such as dentifrices, dietary supplements, and professional applications, but the factor that differentiates them with respect to the prevalence of caries and fluorosis is the $F$ concentration in the community water supply.
\end{abstract}

\section{J Dent Res 67(5):802-806, May 1988}

\section{Introduction.}

Over 40 years ago, in Grand Rapids, Michigan, the first controlled trial of artificial fluoridation of a community water supply for the prevention of dental caries commenced (Dean et al., 1950). Since that time, the successful use of fluoride (F) in various forms and concentrations for the prevention of dental caries has steadily increased. In recent years, the prevalence of dental caries in children has decreased dramatically in the US and other developed countries (NIDR, 1981; Hunter, 1979; Mitropolous and Worthington, 1981; Kalsbeek, 1982; Koch, 1982; O’Mullane, 1982; Brown, 1982; Anderson et al., 1982; Fejerskov et al., 1982; Von der Fehr, 1982), a trend widely attributed to the use of fluorides. With respect to fluorosis, Szpunar and Burt (1987) compared recent fluorosis data with data from Dean's 21-city study (Dean et al., 1941, 1942; Galagan, 1953) with special reference to Dean's comment that ". . from the continuous use of water containing $1.0 \mathrm{ppm}$ F. . the very mildest forms of mottled enamel may occur in about 10 percent of the group." Within the limits of comparison, Szpunar and Burt concluded that there is a slight trend toward more fluorosis today than would be expected based on findings from the late 1930's and early 1940's.

The caries decline, plus the possible increase in fluorosis, has prompted some researchers (Leverett, 1982; Cutress et al.,

Received for publication December 15, 1987

Accepted for publication February 17, 1988

Based on a dissertation submitted to the University of Michigan School of Public Health, in partial fulfillment of the requirements for the DrPH degree

This study was supported by NIH National Research Service Award No. DE 07157.

'Present address: Centers for Disease Control, 1600 Clifton Rd., NE, M.S. E-09, Atlanta, GA 30333
1985) to suggest that the empirically-determined "optimum" $\mathrm{F}$ concentration ranges in drinking waters should be re-assessed. These suggestions come in light of a possible build-up of environmental $\mathrm{F}$ and the widespread availability of $\mathrm{F}$ in many forms. A better understanding of how caries and fluorosis relate to the $\mathrm{F}$ concentration of the water supply and other sources of $F$ is required, however, before any adjustment to the empirically-determined "optimum" concentrations should be recommended.

This paper presents results of a study relating the prevalence of dental caries and fluorosis among Michigan schoolchildren, residing in four different communities, to the various concentrations of $F$ in the communities' water supplies.

\section{Materials and methods.}

Study population. - The four Michigan communities that participated in this study were Cadillac $(0.0 \mathrm{ppm})$, Hudson (0.8 ppm), Redford (1.0 ppm adjusted), and Richmond (1.2 $\mathrm{ppm})$. Average water fluoride concentrations were obtained from the Michigan Department of Public Health's listings of the fluoridation status of communities served by public water supplies for the past 20 years.

Participation was sought from children ages six to 12 years. Classroom teachers distributed and collected permission slips and questionnaire forms that were to be filled out by parents. The questionnaire form requested demographic information, residence history, details of $F$ exposure, and information about the use of dental services and infant nutrition.

Equipment used in the screening included a portable dental chair, Rolux fiber-optic light, mouth mirrors, and no. 23 explorers. One examiner (SMS) collected all data, and a portable computer was used for direct data entry. Children were scored for dental caries by means of the DMFS (dfs) index applied with the criteria of the National Institute of Dental Research (NIDR). Following the caries examination, the Tooth Surface Index of Fluorosis (TSIF) (Horowitz et al., 1984) was applied to measure the prevalence and severity of dental fluorosis. Russell's (1961) criteria for the differential diagnosis of fluorosis were also employed. Results in this paper are restricted to the permanent dentition of continuous-resident children of the four cities.

Statistical analysis. - All statistical analyses were carried out by means of the Michigan Interactive Data Analysis System (MIDAS). The analysis of variance was used to explore differences in mean DMFS values among different age groups, by area of residence, and by use of fluoride sources and dental services. Multiple pair-wise comparisons were performed when indicated by ANOVA results.

Categorical methods were used to determine a list of variables that were consistently associated with caries or fluorosis. Then, these variables, along with the age and education variables, were used as the independent predictors in logistic regression analysis.

The basic formula for the logistic model is:

$$
\mathrm{P}(\mathrm{y})=1 /\left(1+\exp -\left[\mathrm{b}_{\mathrm{o}}+\sum_{i=1}^{k} \mathrm{~b}_{\mathrm{i}} \mathrm{x}_{\mathrm{i}}\right]\right)
$$


where:

$\mathrm{P}(\mathrm{y})$ = probability of experiencing a condition,

$\mathrm{b}_{\mathrm{o}} \quad=\mathrm{a}$ constant,

$b_{i} \quad=$ regression coefficients, and

$\mathrm{x}_{\mathrm{i}} \quad=$ independent predictor variables (Schlesselman, 1982).

The constant and the regression coefficients are estimated by the method of maximum likelihood. In logistic regression, if the independent variable, $x_{i}$, is dichotomous, measured as 1 if exposed and 0 if unexposed, then the antilogarithm of the coefficient is an estimate of the prevalence odds ratio of having the condition, given exposure (Rothman, 1986). For example, the coefficient for a fluoride supplement variable, coded as 1 if supplements were ever used and 0 if never used, may be interpreted as the odds of having fluorosis or caries given exposure to fluoride supplements. For non-dichotomous variables, the antilogarithm of the coefficient is interpreted as the multiplicative change in the odds of having the condition of interest, given a unit change in the independent variable, $x_{i}$ (Rothman, 1986). For example, the antilogarithm of the coefficient for age in years is interpreted as the multiplicative change in the odds of having caries or fluorosis, given a one-year change in age. Further discussion of the derivation and interpretation of the logistic model in epidemiological applications is available in several texts (Kleinbaum et al., 1982; Schlesselman, 1982; Rothman, 1986), and will not be included here.

Intra-examiner reliability. - The examiner received initial training in the TSIF index with the NIDR examiners on an earlier study (Driscoll et al., 1983). Reliability in this Michigan study was based on results of re-examinations of 24 randomly-selected children. The percentage agreement between DMFS scores from the first and second examinations was computed, and Pearson product-moment correlations were computed for first and second examination results for both caries and fluorosis. The kappa statistic (Hunt, 1986) was used to quantify agreement in scoring the presence or absence of fluorosis between the two examinations.

The agreement between the two examinations for DMFS scores was 96\%; scores differed in one child. The Pearson product-moment correlation between DMFS scores from the first and second examinations was $0.92(p<0.01)$. The agreement between first and second examinations for fluorosis (presence/absence) was $92 \%$. For these data, the kappa value was 0.85 , suggesting a high degree of consistency in the recognition of fluorosis (Landis and Koch, 1977; Fleiss, 1981). The Pearson product-moment correlation for the sum of permanent surfaces scored as free from fluorosis was $0.94(p<0.01)$.

\section{Results.}

The total number of subjects examined in this investigation was 1103; 556 of these were continuous residents. Table 1 displays the number of continuous residents by age, gender, and community of residence.

Dental caries. - Table 2 displays the percentage of children who were caries-free and the mean DMFT and DMFS scores of the participants by community of residence. Approximately $65 \%$ of all individuals were free of dental caries, and the percentage of caries-free individuals was significantly associated with the $F$ concentration of the community water supply $(p<0.002)$. For both DMFT and DMFS scores, mean values from Cadillac were significantly higher than mean values from Redford and Richmond, and mean values from Hudson were significantly higher than mean values from Redford.

Dental fluorosis. - For all children, the prevalence of fluorosis was $36.3 \%$. Prevalence figures by community of residence are shown in Table 2 . The data show that as the $\mathrm{F}$
TABLE 1

NUMBER OF CONTINUOUS RESIDENTS BY AGE, GENDER, AND COMMUNITY

\begin{tabular}{lcrrrrrr}
\hline & & & \multicolumn{5}{c}{ Age in Years } \\
\cline { 5 - 8 } Community & Gender & $\mathrm{N}$ & Under 6 & $6-7$ & $8-9$ & $10-11$ & $12+$ \\
\hline Cadillac & $\mathrm{M}$ & 56 & 8 & 21 & 13 & 11 & 3 \\
& $\mathrm{~F}$ & 75 & 6 & 18 & 20 & 25 & 6 \\
Hudson & $\mathrm{M}$ & 60 & 7 & 19 & 17 & 17 & 0 \\
& $\mathrm{~F}$ & 73 & 12 & 25 & 19 & 13 & 4 \\
Redford & $\mathrm{M}$ & 127 & 6 & 61 & 39 & 19 & 2 \\
& $\mathrm{~F}$ & 122 & 11 & 45 & 33 & 27 & 6 \\
Richmond & $\mathrm{M}$ & 18 & 0 & 5 & 9 & 4 & 0 \\
& $\mathrm{~F}$ & 25 & 0 & 10 & 7 & 7 & 1 \\
\hline
\end{tabular}

TABLE 2

PERCENT OF CHILDREN WHO WERE CARIES-FREE, MEAN DMFT AND DMFS SCORES, AND PREVALENCE OF FLUOROSIS, BY COMMUNITY

\begin{tabular}{lcclc}
\hline \hline $\begin{array}{l}\text { Community } \\
\text { Caries-free }\end{array}$ & $\begin{array}{l}\text { Mean } \\
\text { DMFT }\end{array}$ & $\begin{array}{l}\text { Mean } \\
\text { DMFS }\end{array}$ & $\begin{array}{c}\text { Percent with } \\
\text { Fluorosis }^{5}\end{array}$ \\
\hline $\begin{array}{l}\text { Cadillac } \\
(0.0 \mathrm{ppm})\end{array}$ & 55.1 & 1.32 & 1.99 & 12.2 \\
$\begin{array}{l}\text { Hudson } \\
(0.8 \mathrm{ppm})\end{array}$ & 58.3 & $1.04^{2}$ & $1.54^{2}$ & 31.6 \\
$\begin{array}{l}\text { Redford } \\
(1.0 \mathrm{ppm})\end{array}$ & 73.7 & $0.61^{3}$ & $0.87^{3}$ & 49.0 \\
$\begin{array}{l}\text { Richmond } \\
(1.2 \text { ppm) }\end{array}$ & 69.8 & $0.58^{4}$ & $0.74^{4}$ & 51.2 \\
All & 65.4 & 0.88 & 1.28 & 36.3 \\
\hline
\end{tabular}

${ }^{1} \chi^{2}=14.783, \mathrm{df}=2, \mathrm{p}<0.002$.

${ }^{2} \mathrm{DMFT}$ different from Redford, $\mathrm{p}=0.0197$; DMFS, $\mathrm{p}=0.0215$.

${ }^{3}$ DMFT and DMFS different from Cadillac, $p=0.0001$.

${ }^{4}$ DMFT different from Cadillac, $\mathrm{p}=0.0073$; DMFS, $\mathrm{p}=0.0045$. ${ }^{5} \chi^{2}=55.594, \mathrm{df}=3, \mathrm{p}<0.0001$.

TABLE 3

PERCENT PREVALENCE OF FLUOROSIS BY AGE, AND PERCENT DISTRIBUTION OF ALL PERMANENT FLUOROSED SURFACES BY TSIF SCORE

\begin{tabular}{lrcrcc}
\hline \hline $\begin{array}{l}\text { Age } \\
\text { (Yrs.) }\end{array}$ & $\mathrm{N}$ & $\begin{array}{c}\text { \% Prev. } \\
\text { Fluorosis }^{1}\end{array}$ & \multicolumn{3}{c}{ TSIF Score } \\
\hline$<6$ & 50 & 2.0 & 100.0 & 0.0 & - \\
$6-7$ & 204 & 31.9 & 98.5 & 1.5 & - \\
$8-9$ & 157 & 49.7 & 95.8 & 4.2 & - \\
$10-11$ & 123 & 42.3 & 99.0 & 1.0 & - \\
$12+$ & 22 & 27.3 & 100.0 & 0.0 & - \\
\hline
\end{tabular}

${ }^{1} \mathrm{X}^{2}=41.995, \mathrm{df}=4, \mathrm{p}<0.0001$.

concentration of the community water supply increased from near zero to $1.2 \mathrm{ppm}$, the percent prevalence of fluorosis also increased significantly $(p<0.0001)$. The prevalence of fluorosis was not significantly associated with gender, but it increased with age up to the age group 8-10 years, and then decreased (Table 3). The variation in prevalence rates with age may be an artifact, resulting from the relatively small numbers of subjects in the older age groups. Table 3 also shows the distribution of all fluorosed surfaces by TSIF score and age. The mild nature of the fluorosis in the children is underscored by the fact that there was no tooth surface assigned a TSIF score higher than 2. All fluorosed surfaces in Cadillac children were given a TSIF score of 1 , compared with $98.4 \%$ in Hudson, $97.3 \%$ in Redford, and 96.2\% in Richmond.

Stratified analyses. - The associations between the prev- 
alence of dental caries or fluorosis and the $\mathrm{F}$ exposure and dental attendance variables were examined after stratification by community of residence. After stratification, the reported usual frequency of dental visits, age at which parents began to brush their child's teeth, age at start of F rinsing, and the predominant method of feeding during first year of life were not significantly related to caries, partially a result of the reduction in cell sizes in stratified tables. Variables that were not statistically related to the prevalence of fluorosis included the use of $F$ supplements, dental attendance, the time interval since last dental visit, the age at which a child began to brush, the age at which a parent began to brush the child's teeth, age at start of $\mathrm{F}$ rinsing, predominant method of feeding during the first year of life, and source of nutrition during the first year of life. The associations between the $F$ concentration of the community water supply and dental caries or fluorosis remained highly statistically significant, even after stratification, for the majority of the exposure variables studied.

Logistic regression. - To develop the logistic models, we used all of the variables that demonstrated statistically significant associations with the prevalence of caries or fluorosis, as well as variables that were considered theoretically important, as the independent predictors of the prevalence of caries or fluorosis. Coefficients with ratios that were clearly not statistically significant were then dropped from the model, and a new model was fitted with a new, usually smaller, list of independent variables. This model-fitting process continued until a group of independent variables was determined that were theoretically important, or had statistically significant coefficients, or both, and that also explained a large proportion of the variance (as measured by the coefficient of multiple determination, $R^{2}$ ). Automated step-wise procedures are not available for logistic regression in MIDAS; therefore, the statistical software was used iteratively by the analyst.

Table 4 describes the exposures, coefficients, odds ratios, and confidence intervals generated from a model predicting the prevalence of caries in the permanent dentition. The odds ratios for age, dental attendance, and the use of a water supply fluoridated at $1.0 \mathrm{ppm}$ were statistically different from unity. The trends suggested by the odds ratios demonstrate that residence in a $1.0-$ or $1.2-\mathrm{ppm}$ area was protective against dental caries compared with residence in the fluoride-deficient community, Cadillac. The odds ratio for the 0.8 -ppm community, Hudson, indicates that the odds of experiencing caries for Hudson children was similar to that of Cadillac children, after the other variables included in the model are controlled for. In this model, the odds of experiencing dental caries for dental attenders was 9.42 times as great as for children who had never visited the dentist, after all of the other variables included in the model are controlled for. The coefficient of multiple determination,

\section{TABLE 4}

LOGISTIC REGRESSION COEFFICIENTS, ODDS RATIOS, AND 95\% CONFIDENCE LIMITS FOR PREDICTING THE PREVALENCE OF CARIES

\begin{tabular}{|c|c|c|c|c|}
\hline \multirow{2}{*}{$\begin{array}{r}\text { Exposure } \\
\text { Term } \\
\end{array}$} & \multirow{2}{*}{$\begin{array}{l}\text { Regression } \\
\text { Coefficient }\end{array}$} & \multirow{2}{*}{$\begin{array}{l}\text { Odds } \\
\text { Ratio }\end{array}$} & \multicolumn{2}{|c|}{$\begin{array}{l}95 \% \text { Confidence } \\
\text { Limits }\end{array}$} \\
\hline & & & Lower & Upper \\
\hline Constant & -5.915 & & 0.0008 & 0.018 \\
\hline Hudson $(0.8)$ & -0.061 & 1.06 & 0.57 & 1.97 \\
\hline Redford $(1.0)$ & -0.734 & 0.48 & 0.28 & 0.83 \\
\hline Richmond (1.2) & -0.551 & 0.58 & 0.25 & 1.35 \\
\hline Dental Attendance & 2.243 & 9.42 & 2.14 & 41.40 \\
\hline Male Education & -0.278 & 0.76 & 0.56 & 1.02 \\
\hline Age (Years) & 0.428 & 1.53 & 1.35 & 1.74 \\
\hline
\end{tabular}

$-2 \log$ (likelihood) difference $=90.5, \mathrm{df}=6, \mathrm{p}<0.001$.
$\mathrm{R}^{2}$, indicated that about $58 \%$ of the variability in dental caries experience was explained by the independent predictors included in this model.

The coefficients, odds ratios, and confidence limits for a model predicting the prevalence of dental fluorosis are displayed in Table 5. In this model, only the odds ratio for socioeconomic status (male head-of-household education level) was not statistically significant. The odds of experiencing fluorosis increased 3.9 times for children drinking water fluoridated at $0.8 \mathrm{ppm}, 8.5$ times for children drinking optimally fluoridated water, and 7.7 times for children drinking water fluoridated at $1.2 \mathrm{ppm}$. The odds of experiencing fluorosis increased by $57 \%$ for children who had used $F$ rinses (any frequency of use) over children who had never used these rinses, and the odds of experiencing fluorosis tended to increase with age. About $56 \%$ of the variability in dental fluorosis experience could be explained by the variables included in this model.

\section{Discussion.}

Comparisons of questionnaire responses from children who were examined and children who were not examined (but still returned a questionnaire) suggested few differences between the two groups with regard to demographic characteristics and exposure to dental care products and practices. These two groups did differ significantly in some characteristics of dental attendance and oral hygiene practices, suggesting that the nonparticipants were those children receiving more frequent dental care and practicing better oral hygiene at home.

Several of the communities were small, and the further restriction of the study group to continuous-resident children further reduced the study group size. Population mobility, plus the considerable number of children bussed in from outlying rural districts, limited the numbers who fit the continuous residence-community water supply criteria. Dean et al. (Dean and Elvove, 1935; Dean et al., 1939, 1941, 1942) recognized these problems when carrying out their pioneering work on fluorosis, and in the years since their work, these difficulties have only become more acute.

From the crude and stratified analyses of the association between the prevalence of caries and selected exposure factors, a few surprising trends were noted. Children who had used dietary $F$ supplements or had been exposed to professionallyapplied topical fluorides were less likely to be caries-free than were children with no exposure to these $F$ sources. During the model-fitting process, when these variables were included in a logistic model which controlled for community of residence, age, and socio-economic status, the coefficients for these variables were not always significant but were always positive. One explanation for this trend is that susceptible children were

\section{TABLE 5}

LOGISTIC REGRESSION COEFFICIENTS, ODDS RATIOS, AND 95\% CONFIDENCE LIMITS FOR PREDICTING THE PREVALENCE OF FLUOROSIS

\begin{tabular}{|c|c|c|c|c|}
\hline \multirow{2}{*}{$\begin{array}{c}\text { Exposure } \\
\text { Term }\end{array}$} & \multirow{2}{*}{$\begin{array}{l}\text { Regression } \\
\text { Coefficient } \\
\end{array}$} & \multirow{2}{*}{$\begin{array}{l}\text { Odds } \\
\text { Ratio }\end{array}$} & \multicolumn{2}{|c|}{$\begin{array}{l}\text { Confidence } \\
\text { Limits }\end{array}$} \\
\hline & & & Lower & Upper \\
\hline Constant & -4.198 & & 0.005 & 0.05 \\
\hline Hudson $(0.8)$ & 1.364 & 3.91 & 1.98 & 7.73 \\
\hline Redford (1.0) & 2.135 & 8.46 & 4.52 & 15.82 \\
\hline Richmond (1.2) & 2.040 & 7.69 & 3.30 & 17.91 \\
\hline Fluoride Rinse & 0.449 & 1.57 & 1.02 & 2.41 \\
\hline Male Education & 0.045 & 1.05 & 0.81 & 1.35 \\
\hline Age (Years) & 0.222 & 1.25 & 1.13 & 1.38 \\
\hline
\end{tabular}

$-2 \log$ (likelihood) difference $=81.15, \mathrm{df}=6, \mathrm{p}<0.0001$. 
the ones using these products. Another explanation is the presence of a treatment effect, in which children who visited the dentist were more likely to have used supplemental sources of fluoride than were children who did not attend the dentist.

During the model-fitting process, when the dental attendance variable was included, none of the $F$ exposure variables (except $\mathrm{F}$ water) was ever statistically significant. Dental attendance, however, was highly related to the use of the other $F$ products in this data set. These findings support the presence of a treatment effect, suggesting that the dental attendance variable represents not only whether a child receives professional care, but also the likelihood of exposure to other $F$ sources.

The lack of protection against caries in the 0.8-ppm area compared with the fluoride-deficient area cannot be fully explained by differences in socio-economic status or dental attendance, since these factors were controlled, to some extent, in the model. The finding that only about $60 \%$ of the variability in dental caries prevalence was explained by this model, however, suggests that there are more factors which need to be taken into account or that more precise information about exposure needs to be collected to attain full understanding of the variation in caries prevalence.

The prevalence figures from this investigation can be added to those we assessed previously (Szpunar and Burt, 1987). For purposes of comparison with Dean's data, each child with fluorosis in this study was assigned the CFI weight of 1.0 , which corresponds to the "very mild" category of Dean's index (Dean, 1942; Dean, 1946). Because of the use of different study methods and conditions, observed trends need to be accepted cautiously.

Table 6 lists the water F concentration, study group size, CFI score, and prevalence of fluorosis for relevant communities from Dean's 21-city study (Dean et al., 1941; Dean et al., 1942; Galagan, 1953), as well as the results from this investigation. When one compares Richmond $(1.2 \mathrm{ppm})$ with the 1.2 and $1.3 \mathrm{ppm}$ areas surveyed by Dean, it is apparent that the prevalence of fluorosis detected in Richmond was greater than that in Dean's cities. A comparison of the optimally fluoridated areas, Kewanee and Redford, reveals that the percent prevalence and approximate CFI score for Redford were substantially higher than scores from Kewanee. The approximate CFI score and percent prevalence figures from Hudson $(0.8$ ppm) were also higher than the scores from Kewanee. A comparison of Cadillac with the fluoride-deficient areas surveyed

\section{TABLE 6}

COMPARISON OF CFI SCORES AND PERCENT PREVALENCE OF FLUOROSIS IN THE PERMANENT DENTITION OF CONTINUOUS RESIDENT CHILDREN OF SELECTED COMMUNITIES SURVEYED BY DEAN ET AL. AND THE FOUR COMMUNITIES SURVEYED IN MICHIGAN

\begin{tabular}{llllr}
\hline Community & ppm F & $\mathrm{N}$ & CFI & $\begin{array}{r}\% \\
\text { Prev. }\end{array}$ \\
\hline Dean et al. $(1941$, 1942) & & & \\
Joliet, IL & 1.3 & 447 & 0.46 & 25.3 \\
Maywood, IL & 1.2 & 171 & 0.51 & 33.3 \\
Aurora, IL & 1.2 & 633 & 0.32 & 15.0 \\
E. Moline, IL & 1.2 & 152 & 0.49 & 32.0 \\
Kewanee, IL & 0.9 & 123 & 0.31 & 12.2 \\
Evanston, IL & 0.0 & 256 & 0.05 & 1.6 \\
Oak Park, IL & 0.0 & 329 & 0.05 & 0.6 \\
Waukegan, IL & 0.0 & 423 & 0.01 & 0.2 \\
This Study & & & & \\
Richmond, MI & 1.2 & 43 & 0.51 & 51.1 \\
Redford, MI & 1.0 & 249 & 0.48 & 48.1 \\
Hudson, MI & 0.8 & 133 & 0.32 & 32.0 \\
Cadillac, MI & 0.0 & 131 & 0.12 & 12.2 \\
\hline
\end{tabular}

by Dean also indicates a higher prevalence of fluorosis among continuous residents of a fluoride-deficient area today than in Dean's era. The prevalence of fluorosis in fluoride-deficient Cadillac, $12.2 \%$, was precisely the same as that found by Dean in Kewanee, an optimally fluoridated area. The data from the current investigation thus suggest that the prevalence of fluorosis may have increased since Dean's time, although it is less clear whether the severity has also increased. The magnitude of the increase over time may be somewhat overestimated, because of the differences in the indices used. It is likely that many of the teeth assigned a TSIF score of 1 might have been classified as "questionable" (score of 0.5) with Dean's index, and therefore would not have contributed to the prevalence rate under Dean's system.

Table 7 compares the findings of the current investigation with the more recent findings of Driscoll $e t$ al. in Illinois and Iowa (1983, 1986), Segreto et al. in Texas (1984), Leverett in New York (1986), and Aasenden and Peebles in Boston (1974). In general, the prevalence of fluorosis from this investigation was higher than that found in the other cities with comparable water $\mathrm{F}$ concentrations.

The odds ratios from the logistic model demonstrate that the F concentration of the water supply was highly related to the prevalence of fluorosis. Of the other $\mathrm{F}$ sources, only the use of topical $\mathrm{F}$ rinses was significantly related to the prevalence of fluorosis in the logistic regression. The finding that the risk of fluorosis increased by $57 \%$ for $F$ rinse users over non-users is unexpected, given that the majority of children did not report using these rinses until the age of four years or more. By the age of four, crown formation may be nearly complete for the central and lateral incisors as well as for the first molars. There are suggestions that fluorosis may still occur in the late stages of enamel maturation (Larsen et al., 1985; Richards et al., 1986), though more research is needed in this area.

In these data, the use of a $F$ rinse was also significantly related to the use of other $F$ products and dental care practices. Fluoride rinsers may be the most dentally aware children, and

TABLE 7

COMPARISON OF CFI SCORES AND PERCENT PREVALENCE OF

FLUOROSIS FROM SELECTED RECENT STUDIES AND THE FOUR MICHIGAN COMMUNITIES

\begin{tabular}{llrrr}
\hline & ppm F & N & CFI & $\begin{array}{r}\% \\
\text { Prev. }\end{array}$ \\
\hline Driscoll et al. $(1983$, 1986) & & & & \\
Kewanee, IL & 0.9 & 336 & 0.39 & 14.6 \\
4 lowa Towns & 0.0 & 316 & 0.06 & 2.9 \\
Segreto et al. (1984) & & & & \\
Angleton, TX & 1.3 & 187 & 0.59 & 32.7 \\
Alvin, TX & 1.3 & 211 & 0.47 & 28.9 \\
Kingsville, TX & 1.0 & 361 & 0.53 & 39.4 \\
San Antonio, TX & 0.4 & 126 & 0.05 & 2.4 \\
San Marcos, TX & 0.3 & 223 & 0.14 & 8.5 \\
N. Braunfels, TX & 0.3 & 103 & 0.26 & 8.7 \\
Leverett (1986) & & & & \\
Fluoridated NY & 1.0 & 729 & - & 26.9 \\
Unfluoridated NY & 0.0 & 564 & - & 4.4 \\
Aasenden and Peebles (1974) & & & & \\
F Water Control & 1.0 & 92 & 0.40 & 32.6 \\
This Study & & & & \\
Richmond, MI & 1.2 & 43 & 0.51 & 51.1 \\
Redford, MI & 1.0 & 249 & 0.48 & 48.1 \\
Hudson, MI & 0.8 & 133 & 0.32 & 32.0 \\
Cadillac, MI & 0.0 & 131 & 0.12 & 12.2 \\
\hline
\end{tabular}


thus have the greatest frequency of exposure to $F$ products that could be ingested.

To summarize, the data suggest that children in the four Michigan cities may be ingesting similar levels of $F$ from combinations of dentifrices, mouthrinses, supplements, and professional applications, but the factor that differentiates them with respect to caries and fluorosis is the $F$ concentration of the community water supply. The results from this investigation also suggest that $\mathrm{F}$ consumption from multiple sources may have increased since Dean's time (the late 1930's and early 1940's), and provide further evidence of the low level of dental caries being experienced by many children today.

The value of re-examining currently recommended $F$ concentrations in drinking water to reduce fluorosis should be balanced against the clear evidence (Table 2) that caries is inversely related to the $\mathrm{F}$ concentration. The very mild fluorosis seen in the Michigan communities was clearly not perceived as a problem by the children or their families, and it would be an exaggeration to call the fluorosis seen here a public health problem. At the same time, our results question the marketing of high-F dentifrices, which can only increase fluorosis with slight decreases in the already-low prevalence of caries. The policy issue, however, does require continued re-monitoring of both caries and fluorosis, and further investigation into total fluoride intake from all sources.

\section{REFERENCES}

AASENDEN, R. and PEEBLES, T.C. (1974): Effects of Fluoride Supplementation from Birth on Human Deciduous and Permanent Teeth, Arch Oral Biol 19:321-326.

ANDERSON, R.J.; BRADNOCK, G.; BEAL, J.F.; and JAMES, P.M.C. (1982): The Reduction of Dental Caries Prevalence in English Schoolchildren, $J$ Dent Res 61:1305-1310.

BROWN, R.H. (1982): Evidence of Decrease in the Prevalence of Dental Caries in New Zealand, $J$ Dent Res 61:1327-1330.

CUTRESS, T.W.; SUCKLING, G.W.; PEARCE, E.I.F.; and BALL, M.E. (1985): Defects of Tooth Enamel in Children in Fluoridated and Nonfluoridated Areas of the Auckland Region, $N Z$ Dent $J$ 81:12-19.

DEAN, H.T. (1942): The Investigation of Physiological Effects by the Epidemiological Method. In: Fluorine and Dental Health, Publ. 19, American Association for the Advancement of Science, pp. 23-32.

DEAN, H.T. (1946): Epidemiological Studies in the United States. In: Dental Caries and Fluorine, American Association for the Advancement of Science.

DEAN, H.T.; ARNOLD, F.A.; and ELVOVE, E. (1942): Domestic Water and Dental Caries. V. Additional Studies of the Relation of Fluoride Domestic Waters to Dental Caries in 4425 White Children, Age 12-14 Years, of 13 Cities in 4 States, Pub Health Rep $57: 1155-1179$.

DEAN, H.T.; ARNOLD, F.A.; JAY, P.; and KNUTSON, J.W. (1950): Studies on Mass Control of Dental Caries through Fluoridation of the Public Water Supply, Pub Health Rep 65:1403-1408.

DEAN, H.T. and ELVOVE, E. (1935): Studies on the Minimal Threshold of the Dental Sign of Chronic Endemic Fluorosis (Mottled Enamel), Pub Health Rep 50:1719-1729.

DEAN, H.T.; JAY, P.; ARNOLD, F.A.; and ELVOVE, E. (1941): Domestic Waters and Dental Caries. II. A Study of 2832 White Children Ages 12-14 Years of Eight Suburban Chicago Communities, Including Lactobacillus acidophilus Studies of 1761 Children, Pub Health Rep 56:761-792.

DEAN, H.T.; JAY, P.; ARNOLD, F.A.; McCLURE, F.J.; and ELVOVE, E. (1939): Domestic Waters and Dental Caries Including Certain Epidemiological Aspects of Oral Lactobacillus acidophilus, Pub Health Rep 54:862-888.

DRISCOLL, W.S.; HOROWITZ, H.S.; MEYERS, R.J.; HEIFETZ,
S.B.; KINGMAN, A.; and ZIMMERMANN, E.R. (1983): Prevalence of Dental Caries and Dental Fluorosis in Areas with Optimal and Above-optimal Water Fluoride Concentrations, $J$ Am Dent Assoc 107:42-47.

DRISCOLL, W.S.; HOROWITZ, H.S.; MEYERS, R.J.; HEIFETZ, S.B.; KINGMAN, A.; and ZIMMERMANN, E.R. (1986): Prevalence of Dental Caries and Dental Fluorosis in Areas with Negligible, Optimal, and Above-optimal Fluoride Concentrations in Drinking Water, I Am Dent Assoc 113:29-33.

FEJERSKOV, O.; ANTOFT, P.; and GADEGAARD, E. (1982): Decrease in Caries Experience in Danish Children and Young Adults in the 1970's, J Dent Res 61:1305-1310.

FLEISS, J.L. (1981): Statistical Methods for Rates and Proportions, 2nd ed., New York: John Wiley and Sons.

GALAGAN, D.J. (1953): Climate and Controlled Fluoridation, $J$ Am Dent Assoc 47:159-170.

HOROWITZ, H.S.; DRISCOLL, W.S.; MEYERS, R.J.; HEIFETZ, S.B.; and KINGMAN, A. (1984): A New Method for Assessing the Prevalence of Dental Fluorosis - The Tooth Surface Index of Fluorosis, $J$ Am Dent Assoc 109:37-41.

HUNT, R.J. (1986): Percent Agreement, Pearson's Correlation, and Kappa as Measures of Inter-examiner Reliability, $J$ Dent Res 65:128130.

HUNTER, P.B. (1979): The Prevalence of Dental Caries in 5-YearOld New Zealand Children, NZ Dent J 75:154-157.

KALSBEEK, H. (1982): Evidence of Decrease in Prevalence of Dental Caries in The Netherlands: An Evaluation of Epidemiological Caries Surveys in 4-6- and 11-15-year-old Children, Performed Between 1965 and 1980, J Dent Res 61:1321-1326.

KLEINBAUM, D.G.; KUPPER, L.L.; and MORGENSTERN, $\mathrm{H}$. (1982): Epidemiologic Research, Belmont, CA: Lifetime Learning Publications, pp. 419-438.

KOCH, G. (1982): Evidence for Declining Caries Prevalence in Scotland, $J$ Dent Res 61:1327-1330.

LANDIS, J.R. and KOCH, G.G. (1977): The Measure of Observer Agreement for Categorical Data, Biometrics 33:149-174.

LARSEN, M.J.; RICHARDS, A.; and FEJERSKOV, O. (1985): Development of Dental Fluorosis According to Age at Start of Fluoride Administration, Caries Res 19:519-527.

LEVERETT, D.H. (1982): Fluorides and the Changing Prevalence of Dental Caries, Science 217:26-30.

LEVERETT, D.H. (1986): Prevalence of Dental Fluorosis in Fluoridated and Nonfluoridated Communities - A Preliminary Investigation, J Publ Hlth Dent 46:184-187.

MITROPOLOUS, C.M. and WORTHINGTON, H.V. (1981): Statistical Aspects of Caries Prevalence Data Over a 12-Year Period in English Schoolchildren, IADR Prog \& Abst 60: No. 60.

NATIONAL CARIES PROGRAM, NATIONAL INSTITUTE OF DENTAL RESEARCH (1981): The Prevalence of Dental Caries in US Children 1979-80, The National Dental Caries Prevalence Survey. NIH Publ. No. 82-2245.

O'MULLANE, D.M. (1982): The Changing Patterns of Dental Caries in Irish Schoolchildren Between 1961 and 1981, J Dent Res 61:13171320.

RICHARDS, A.; KRAGSTRUP, J.; JOSEPHSEN, K.; and FEJERSKOV, O. (1986): Dental Fluorosis Developed in Post-secretory Enamel, J Dent Res 65:1406-1409.

ROTHMAN, K.J. (1986): Modern Epidemiology, Boston: Little, Brown, and Company, pp. 289-298.

RUSSELL, A.L. (1961): The Differential Diagnosis of Fluoride and Nonfluoride Opacities, J Publ Hlth Dent 21:143-146.

SCHLESSELMAN, J.J. (1982): Case-Control Studies: Design, Conduct, Analysis, New York: Oxford University Press.

SEGRETO, V.A.; COLLINS, E.M.; CAMANN, D.; and SMITH, C.T. (1984): A Current Study of Mottled Enamel in Texas, $J$ Am Dent Assoc 108:56-59.

SZPUNAR, S.M. and BURT, B.A. (1987): Trends in the Prevalence of Dental Fluorosis in the United States: A Review, $J$ Publ Hlth Dent 47:71-79.

VON DER FEHR, F.R. (1982): Evidence of Decreasing Caries Prevalence in Norway, $J$ Dent Res 61:1331-1335. 